\title{
MICROALBUMINURIA PREDICTS RENAL AND CARDIOVASCULAR DYSFUNCTION IN PATIENTS WITH TYPE 2 DIABETES MELLITUS
}

\author{
Fathima Beevi Osman'1, Bindu Gopinathan Nair²
}

${ }^{1}$ Associate Professor, Department of Biochemistry, Government Medical College, Thiruvananthapuram. ${ }^{2}$ Associate Professor, Department of Biochemistry, Government Medical College, Thiruvananthapuram.

\section{ABSTRACT}

\section{BACKGROUND}

The presence of microalbuminuria in Type 2 Diabetes Mellitus (T2DM) represents a more generalised vascular pathology. Microalbuminuria is an early marker of subclinical renal dysfunction and cardiovascular disease in patients with T2DM.

\section{MATERIALS AND METHODS}

Microalbuminuria expressed as Albumin Creatinine Ratio (ACR) and fasting blood glucose (FBS) estimated in T2DM patients $(n=31)$ and normal controls $(n=50)$. Renal function parameters like urea, creatinine, total protein, albumin, and lipid parameters like total cholesterol, triglycerides, HDL cholesterol and LDL cholesterol estimated in fasting blood sample and creatinine clearance calculated. Mean and standard deviation of these values calculated and compared in the two groups using unpaired test. The correlation of Microalbuminuria with renal function and lipid parameters were studied by Pearson's correlation coefficient.

\section{RESULTS}

In T2DM, Microalbuminuria was significantly higher $(91.2 \pm 61.1 \mathrm{mg} / \mathrm{g}$ of creatinine) than in controls $(15.08 \pm 5.5 \mathrm{mg} / \mathrm{g} ; \mathrm{p}$ value $<0.001$ ) and showed significant positive correlation with fasting blood glucose ( $r=0.65 ; \mathrm{p}<0.001$ ), serum creatinine, blood urea and significant negative correlation with creatinine clearance which are indicators of renal dysfunction. Microalbuminuria also showed positive correlation with serum total cholesterol, triglycerides and LDL cholesterol which are indicators of cardiovascular disease.

\section{CONCLUSION}

Microalbuminuria is a useful early marker of renal dysfunction and cardiovascular disease in patients with T2DM.

\section{KEYWORDS}

Microalbuminuria, T2DM, Renal Dysfunction, Cardiovascular Dysfunction.

HOW TO CITE THIS ARTICLE: Osman FB, Nair BG. Microalbuminuria predicts renal and cardiovascular dysfunction in patients with type 2 diabetes mellitus. J. Evolution Med. Dent. Sci. 2017;6(8):605-608, DOI: 10.14260/Jemds/2017/129

\section{BACKGROUND}

The worldwide prevalence of diabetes mellitus has increased dramatically over the past two decades and the prevalence of T2DM is expected to rise more rapidly in the future because of increasing obesity and reduced activity levels. Microalbuminuria defined by a urinary albumin excretion rate which is elevated but below the level of Clinistix detection (30 - $300 \mathrm{mg} / 24$ hours) is predictive of cardiovascular disease in both $\mathrm{T} 1$ and T2DM as well as being predictive of later development of overt nephropathy and chronic renal failure.(1-7) Two major factors that normally limit the loss of urinary proteins are the pore size and charge of basement membrane. Sialoproteins in the glomerular capillary walls are negatively charged which explains why albumin with an effective molecular diameter of $7 \mathrm{~nm}$ and strongly anionic is being repulsed by the glomerular filtration barrier. Filtration is increased if anionic groups are blocked by glycosylation in patients with diabetes mellitus. The flow of the glomerular filtrate is thought to follow an extracellular

Financial or Other, Competing Interest: None.

Submission 19-12-2016, Peer Review 11-01-2017,

Acceptance 18-01-2017, Published 25-01-2017.

Corresponding Author:

Dr. Fathima Beevi Osman,

Associate Professor,

Department of Biochemistry,

Government Medical College,

Thiruvananthapuram.

E-mail: drfathimasalim@gmail.com

DOI: $10.14260 /$ jemds $/ 2017 / 129$

\section{(c) $(1) \Theta$}

route, passing through the endothelial fenestrae, then across the glomerular basement membrane and finally through the slit diaphragm between the foot processes of podocytes. It has been recently hypothesised that microalbuminuria leading to proteinuria and end stage renal disease is mainly due to an altered glomerular filtration barrier at the podocyte level. However, arterial hypertension and abnormalities of blood lipid concentrations and structure are also important antecedents of such complications in diabetes mellitus. It has been suggested that hyperglycaemia, arterial hypertension and dyslipidaemia cause disorders of the albumin excretion rate by damaging the podocyte and slit diaphragm protein scaffold with overproduction of and extracellular release of oxygen radical species at the glomerular level.(8) Rather than estimating albumin level in 24-hour urine, a more convenient alternative is to determine, in early morning sample, the ratio of albumin to creatinine index. Creatinine concentration is relatively constant in any subject and the index correlates well with the 24-hour total excretion of albumin. Normal albumin to creatinine ratio (ACR) is $<30 \mathrm{mg} / \mathrm{g}$ of creatinine. Microalbuminuria is said to exist between 30 and $300 \mathrm{mg} / \mathrm{g}$ of creatinine and is of value as an index of vascular damage in diabetes mellitus. Mogensen, Nelson and colleagues have shown that microalbuminuria predicts risk of developing diabetic nephropathy which can be reversed by strict glycaemic control. Detection of microalbuminuria helps to suspect renal disease, assess its severity, predicts the prognosis and monitors the response to therapy with ACE inhibitors or Angiotensin II antagonist in slowing the 
progress to nephropathy. Microalbuminuria is the strongest independent risk factor of cardiovascular disease.

\section{MATERIALS AND METHODS}

The patients chosen for the study were those attending the nephrology outpatient clinic of Medical College Hospital, Thiruvananthapuram $(n=31)$. Patients with frank proteinuria were excluded from the study. Comparative group consists of age and sex matched healthy normal controls $(n=50)$. Albumin excretion was estimated in the first morning midstream urine samples collected in clean bottles using turbidimetric immunoassay. ${ }^{(9-10)}$ Urine creatinine was estimated by Jaffe's method and the results were expressed as albumin creatinine ratio (ACR). Urine was retested over the following three months if the result indicated microalbuminuria. If the urine albumin to creatinine ratio was between 30 and $300 \mathrm{mg} / \mathrm{g}$ on two occasions over a period of three months, a diagnosis of microalbuminuria was made. $6 \mathrm{~mL}$ of fasting blood samples were also collected from patients and controls under strict aseptic precautions for estimation of glucose, urea, creatinine, total protein, albumin, total cholesterol, HDL cholesterol and triglycerides. From the values of total cholesterol, HDL cholesterol and triglycerides, value of LDL cholesterol was determined using the Friedewald's formula.(11) Quantitative data were expressed as mean and standard deviation. Statistical analysis was done using SPSS version 22.0. Comparison of different parameters between the two groups was determined using unpaired $t$ test. The correlation of microalbuminuria with fasting blood glucose and renal function parameters like blood urea, serum creatinine, urine creatinine and creatinine clearance and lipid parameters like total cholesterol, triglycerides, HDL cholesterol and LDL cholesterol studied by Pearson's correlation coefficient.

\section{RESULTS}

The study group consisted of 31 T2DM patients and 50 healthy normal controls. The mean fasting blood glucose (FBS) of diabetic group was $125.25 \pm 26.13 \mathrm{mg} \%$ and that of the control group was $76.52 \pm 6.21 \mathrm{mg} \%$ (table 1). The observed difference in FBS value was statistically significant ( $p<0.001)$. Microalbuminuria showed a direct relation with duration of diabetes. $33.3 \%$ patients who were diabetic for less than 3 years showed microalbuminuria. This increased to $72.7 \%$ in patients who were diabetic for $3-5.9$ years, $88.9 \%$ in patients who were diabetic for $6-8.9$ years and $100 \%$ in those patients who were diabetic for more than 9 years. The mean blood urea levels in T2DM patients was $37.39 \pm 7.7 \mathrm{mg} \%$ and that of control group was $21.84 \pm 3.73 \mathrm{mg} \%$ which was also statistically significant $(\mathrm{p}<0.001)$. Similarly, serum creatinine, urine creatinine, creatinine clearance, serum proteins and serum albumin showed statistically significant difference when compared to controls (Table 1).

Correlation between ACR and other study parameters was done using Pearson's correlation. ACR showed significant positive correlation with FBS, the renal function parameters like blood urea, serum creatinine and significant negative correlation with urine creatinine, creatinine clearance, serum proteins and serum albumin (Table 2). ACR also showed significant positive correlation with cardiovascular markers like serum total cholesterol, serum triglycerides and serum LDL cholesterol (Table 2).

\begin{tabular}{|c|c|c|c|c|c|c|c|}
\hline \multirow{2}{*}{$\begin{array}{c}\text { Sl. } \\
\text { No. }\end{array}$} & \multirow{2}{*}{ Study Variables } & \multicolumn{2}{|c|}{ DM (N=31) } & \multicolumn{2}{c|}{ Control (N=50) } & \multirow{2}{*}{ t } & \multirow{2}{*}{ p } \\
\cline { 3 - 6 } & Mean & SD & Mean & SD & & \\
\hline 1 & Microalbuminuria (mg/g of creatinine) & 91.29 & 61.1 & 15.08 & 5.5 & 6.927 & $<0.001$ \\
\hline 2 & Blood urea (mg \%) & 37.39 & 7.7 & 21.84 & 3.73 & 10.506 & $<0.001$ \\
\hline 3 & Serum Creatinine (mg \%) & 1.3 & 0.39 & 0.71 & 0.35 & 7.057 & $<0.001$ \\
\hline 4 & Urine Creatinine (mg \%) & 100.77 & 12.96 & 123.92 & 7.41 & 9.068 & $<0.001$ \\
\hline 5 & Creatinine Clearance (mL/min.) & 70.52 & 21.19 & 121.26 & 17.58 & 11.662 & $<0.001$ \\
\hline 6 & Serum Protein (g \%) & 6.58 & 0.47 & 6.98 & 0.2 & 4.494 & $<0.001$ \\
\hline 7 & Serum albumin (g \%) & 3.56 & 0.36 & 3.95 & 0.15 & 5.735 & $<0.001$ \\
\hline 8 & Fasting blood glucose (mg \%) & 125.25 & 26.13 & 76.52 & 6.21 & 10.206 & $<0.001$ \\
\hline 9 & Serum total cholesterol (mg \%) & 233.65 & 33.24 & 176.17 & 25.95 & 8.689 & $<0.001$ \\
\hline 10 & Serum triglyceride (mg \%) & 144.73 & 73.3 & 105.68 & 51.82 & 2.591 & 0.013 \\
\hline 11 & HDL (mg \%) & 40 & 8 & 49 & 8.09 & 4.887 & $<0.001$ \\
\hline 12 & LDL (mg \%) & 158 & 29.8 & 106 & 24.47 & 8.545 & $<0.001$ \\
\hline
\end{tabular}

Table 1. Comparison of Microalbuminuria, Renal function parameters and Cardiovascular markers in T2DM and Controls

\begin{tabular}{|c|c|c|c|}
\hline \multirow{2}{*}{$\begin{array}{l}\text { Sl. } \\
\text { No. }\end{array}$} & \multirow{2}{*}{$\begin{array}{c}\text { Correlation between ACR } \\
\text { and other Parameters }\end{array}$} & \multicolumn{2}{|c|}{ Pearson Correlation } \\
\hline & & $\mathrm{R}$ & $\mathrm{p}$ \\
\hline 1 & FBS & 0.65 & $<0.001$ \\
\hline 2 & Blood Urea & 0.748 & $<0.001$ \\
\hline 3 & Serum Creatinine & 0.783 & $<0.001$ \\
\hline 4 & Urine Creatinine & -0.681 & $<0.001$ \\
\hline 5 & Creatinine Clearance & -0.667 & $<0.001$ \\
\hline 6 & Total Protein & -0.652 & $<0.001$ \\
\hline 7 & Serum albumin & -0.737 & $<0.001$ \\
\hline 8 & Total cholesterol & 0.488 & $<0.001$ \\
\hline 9 & Triglyceride & 0.278 & 0.001 \\
\hline 10 & LDL cholesterol & 0.469 & $<0.001$ \\
\hline
\end{tabular}

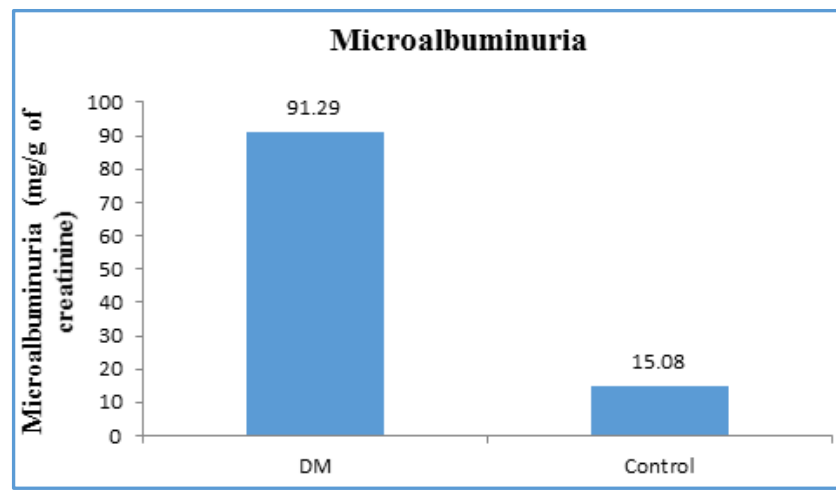

Graph 1. Comparison of Mean Values of Microalbuminuria in T2DM and Controls 


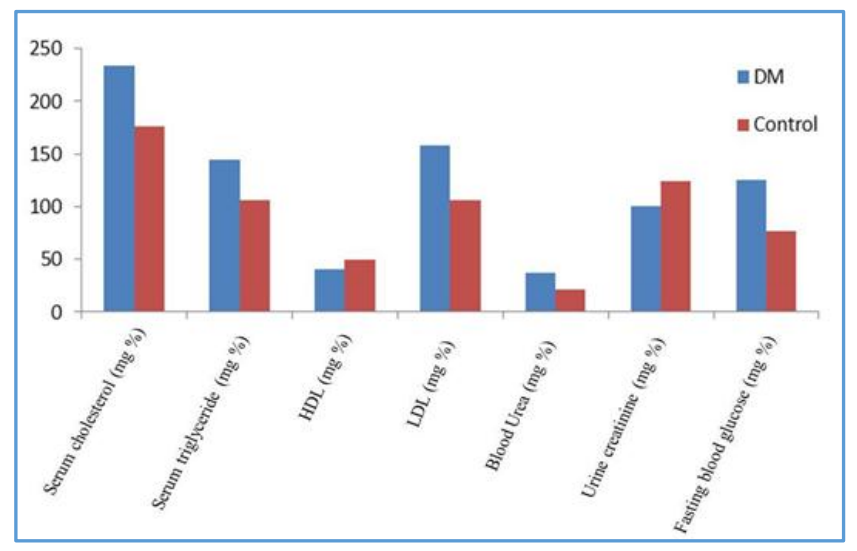

Graph 2. Lipid and Renal Function Parameters in T2DM and Controls

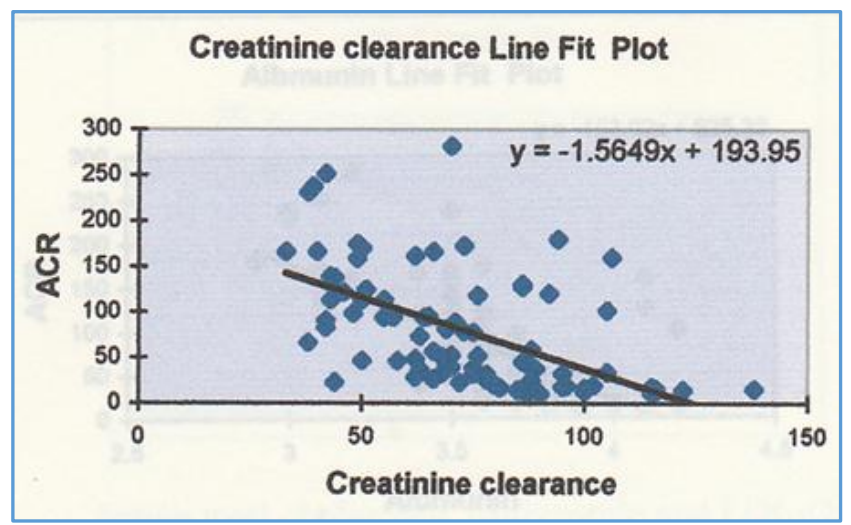

Figure 1. Correlation of ACR with Creatinine Clearance

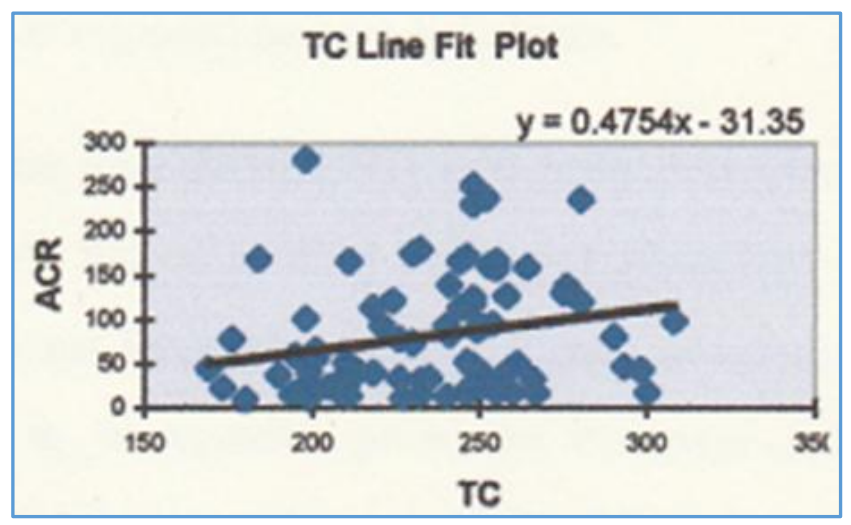

Figure 2. Correlation of ACR with Total Cholesterol (TC)

\section{DISCUSSION}

The mean albumin creatinine ratio in the control group was $15.08 \pm 5.5 \mathrm{mg} / \mathrm{g}$ of creatinine which is similar to the results of Comper W D, Osicka and Jerums.(12) A comparative study in New Castle, UK showed a higher urinary albumin in UK South Asians including Indians than Europeans.(13) Microalbuminuria was significantly increased in patients with T2DM $(91.29 \pm 61.1 \mathrm{mg} / \mathrm{g}$ of creatinine) which is similar to earlier studies,(14) study by Hong et al examined urinary microalbumin in T2DM Asian subjects including Indians,(15) NHANES (16) and the HOPE study.(17) The HOPE investigators showed that people with T2DM at high risk of cardiovascular disease but without overt nephropathy have a significant although slow course of renal insufficiency. It also showed an increased risk of major cardiovascular events at increased levels of urinary albumin excretion including levels within the normal range.(18) The use of ACE inhibitor, Ramipril prevents or delays the progression of albuminuria(19) although the effect of ACE inhibitor was not included in the present study. In our study, it was seen that as age of the patient increased the percentage showing microalbuminuria increased significantly and correlated with earlier studies. Several studies showed that urinary microalbumin was directly related to duration, severity and control of diabetes. Hyperglycaemia is linked to vascular dysfunction in patients with diabetes either directly or through advanced glycation end products formation.(20) In the present study, also FBS positively correlated with microalbuminuria (Table 2).

There was significant positive correlation between ACR and blood urea levels ( $p<0.001$ ) (Table 2), between ACR and serum creatinine $(\mathrm{p}<0.001)$ (Table 2$)$ and significant negative correlation between ACR and urine creatinine and ACR and creatinine clearance in our study.(21-22) Significant negative correlation was found between ACR and serum total protein and ACR and serum albumin in the present study. Renal dysfunction detected by presence of microalbuminuria and minor decrease of creatinine clearance has been identified a novel indicator and potential promoter of cardiovascular risk in a study by Ritz et al.(23) In the present study, there was significant positive correlation between microalbuminuria and total cholesterol, triglycerides and LDL cholesterol ( $p$ $<0.001$ ). Similar results were obtained in a study by Bakris et al in people with T2DM.(24) Both the Multiple Risk Factor Intervention Trial (MRFIT) and UKPDS confirmed the close relationship between total cholesterol level and elevated risk of cardiovascular events. Another study by Leoncini et al showed that mild renal dysfunction was related to presence of several risk factors such as old age, higher blood pressure and lipid status and evaluation of urinary albumin excretion and creatinine clearance could be useful for identifying subjects at higher cardiovascular risk. (25) Hence, the current study on microalbuminuria establishes an early indicator of subclinical renal dysfunction and cardiovascular dysfunction and predicts the prognosis to initiate early and prompt intervention.

\section{CONCLUSION}

The present study has demonstrated higher levels of microalbuminuria in patients with T2DM which is significantly correlated with renal function parameters like blood urea, serum creatinine, urine creatinine and creatinine clearance as it is a reliable indicator for detection of renal dysfunction in the early stages in the risk population so that prompt and scrupulous management can be initiated to effectively reduce the morbidity and mortality. Microalbuminuria is significantly correlated with dyslipidaemia characterised by elevated total cholesterol, LDL cholesterol, triglycerides and decreased HDL cholesterol in the study group. Thus, microalbuminuria, an early marker of mild renal dysfunction, also contributes to increased cardiovascular risk.

\section{REFERENCES}

[1] Sacks DB, Arnold M, Bakris GL, et al. Guidelines and recommendations for laboratory analysis in the diagnosis and management of diabetes mellitus. Diabetes Care 2011;34(6):e61-e99. 
[2] KDIGO. Chapter 1: Definition and classification of CKD. Kidney Int Suppl 2013;3:19. http://www.kdigo.org/clinical practice guidelines/ pdf/CKD/ KDIGO 2012 CKD GL.pdf

[3] Gross JL, de Azevedo MJ, Silveiro SP, et al. Diabetic nephropathy: diagnosis, prevention and treatment. Diabetes Care 2005;28(1):164-76.

[4] Ruggenenti P, Remuzzi G. Nephropathy of type-2 diabetes mellitus. J Am Soc Nephrol 1998;9:2157-69.

[5] Ismail N, Becker B, Strzelczyk P, et al. Renal disease and hypertension in non-insulin-dependent diabetes mellitus. Kidney Int 1999;55(1):1-28.

[6] Mogensen CE. Prediction of clinical diabetic nephropathy in IDDM patients. Alternatives to microalbuminuria? Diabetes 1990;39(7):761-7.

[7] Bakris GL, Molitch M. Microalbuminuria as a risk predictor in diabetes: the continuing saga. Diabetes Care 2014;37(3):867-75.

[8] Nosadini R, Tonolo G. Blood glucose and lipid control as risk factors in the progression of renal damage in type 2 diabetes. J Nephrol 2003;16(Suppl 7):S42-7.

[9] Landgraf-Leurs MM, Modi E, Horn $\mathrm{K}$, et al. Immunoturbidimetric assay for the determination of microalbuminuria using the Hitachi analyser. J Clin Chem Clin Biochem 1987;25(10):683-7.

[10] Schmitz A, Vaeth M. Microalbuminuria: a major risk factor in non-insulin-dependent diabetes. A 10-year follow-up study of 503 patients. Diabetic medicine 1988;5(2):126-34.

[11] Friedewald WT, Levy RI, Fredrickson DS. Estimation of the concentration of low-density lipoprotein cholesterol in plasma, without use of the preparative ultracentrifuge. Clin Chem 1972;18(6):499-502.

[12] Comper WD, Osicka TM, Jerums G. High prevalence of immune-unreactive intact albumin in urine of diabetic patients. Am J Kidney Dis 2003;41(2):336-42.

[13] Fischbacher CM, Bhopal R, Rutter MK, et al. Microalbuminuria is more frequent in South Asian than in European origin populations: a comparative study in Newcastle, UK. Diabet Med 2003;20(1):31-6.

[14] Gaede P, Vedel P, Larsen N, et al. Multifactorial intervention and cardiovascular disease in patients with type 2 diabetes. N Engl J Med 2003;348(5):383-93.
[15] Hong CY, Hughes K, Chia KS, et al. Urinary alpha 1 microglobulin as a marker of nephropathy in type 2 diabetic Asian subjects in Singapore. Diabetic Care 2003;26(2):338-42.

[16] Wrone EM, Carnethon MR, Palaniappan L, et al. Association of dietary protein intake and microalbuminuria in healthy adults: Third National Health and Nutrition Examination Survey. Am J Kidney Disease 2003;41(3):580-7.

[17] Mann JF, Gerstein HC, Yi QL, et al. Progression of renal insufficiency in type 2 diabetes with and without microalbuminuria: results of the Heart Outcomes Prevention Evaluation (HOPE) randomized study. Am J of Kidney Diseases 2003;42(5):936-42.

[18] Qin QP, Peltola 0, Pettersson K. Time resolved fluorescence resonance energy transfer assay for point of care testing of urinary albumin. Clin Chem 2003;49(7):1105-113.

[19] Mann JF, Gerstein HC, Yi QL, et al. Development of renal disease in people at high cardiovascular risk: results of HOPE randomized study. J Am Soc Nephrol 2003;14(3): 641-7.

[20] Wautier MP, Massin P, Guillausseau PJ, et al. N (Carboxy methyl) lysine as a biomarker for microvascular complications in type 2 diabetic patients. Diabetes Metab 2003;29(1):44-52.

[21] Lane JT. Microalbuminuria as a marker of cardiovascular and renal risk in type 2 diabetes mellitus: a temporal perspective. Am J Physiol Renal Physiol 2004;286(3):F442-F50.

[22] Rippin JD, Barnett AH, Bain SC. Cost effective strategies in the prevention of diabetic nephropathy. Pharmacoeconomics 2004;22(1):9-28.

[23] Ritz E. Renal dysfunction: a novel indicator and potential promoter of cardiovascular risk. Clin Med 2003;3(4):357-60.

[24] Bakris GL, Smith AC, Richardson DJ, et al. Impact of an ACE inhibitor and calcium antagonist on microalbuminuria and lipid subfractions in type 2 diabetes, a randomized, multicentre pilot study. J Hum Hypertens 2002;16(3):185-91.

[25] Leoncini G, Viazzi F, Parodi D, et al. Mild renal dysfunction and subclinical cardiovascular damage in primary hypertension. Hypertension 2003;42(1): 14-8. 